\title{
A grande recessão brasileira: diagnóstico e uma agenda de política econômica
}

JOSÉ LUIS OREIRO ${ }^{I}$

\section{Introdução: antecedentes da grande recessão}

1 GRANDE recessão iniciada no segundo trimestre de 2014 é a mais profunda e duradoura queda do nível de atividade econômica desde o término da Segunda Guerra Mundial. ${ }^{1}$ Com efeito, entre o segundo trimestre de 2014 e o terceiro trimestre de 2016, o PIB brasileiro apresentou uma queda de $8,33 \%$ de acordo com os dados do Ipeadata. No momento em que escrevo este artigo, os dados do PIB do quarto trimestre ainda não foram divulgados, mas as estimativas existentes com base no índice de atividade econômica do Banco Central do Brasil apontam para a continuidade do movimento de queda do nível de atividade econômica no último trimestre do ano passado, com uma queda de 0,36\% com relação ao trimestre imediatamente anterior (Valor Econômico, 2017a).

Na Figura 1 podemos visualizar o comportamento do PIB real no Brasil no período compreendido entre o primeiro trimestre de 2003 e o terceiro trimestre de 2016. Aplicando uma linha de tendência linear aos dados, observa-se que a economia brasileira apresentou uma tendência de crescimento de $0,94 \%$ por trimestre, o que equivale a uma taxa anualizada de crescimento de $3,78 \%$.

A inspeção da Figura 1 nos permite também constatar que entre 2003 e 2006 a economia brasileira operava ligeiramente abaixo de sua tendência de longo prazo. A partir de 2007, contudo, essa situação se inverte e a economia brasileira passa a operar acima de sua tendência, exceto por um breve período entre o final de 2008 e o início de 2009, o qual compreende os efeitos da crise financeira internacional. Essa inversão no sinal do hiato do produto decorre da flexibilização do tripé macroeconômico após 2006, com a eliminação da sistemática de metas declinantes de inflação, redução da meta de superávit primário e adoção de uma regra de valorização do salário mínimo (Oreiro, 2016, cap.8).

A flexibilização do tripé macroeconômico viabilizou uma notável aceleração do crescimento da economia brasileira em 2010. Conforme podemos verificar na Figura 2, o crescimento do PIB nos dois primeiros trimestres de 2010, na comparação com o mesmo período do ano anterior, supera a marca de $8 \%$.

A partir de 2011, contudo, observa-se uma desaceleração do ritmo de crescimento da economia brasileira. Com efeito, no último trimestre de 2014 
o crescimento do PIB real havia se reduzido para 2,63\% na comparação com o último trimestre de 2010. A desaceleração do crescimento continua até o segundo trimestre de 2012, quando o PIB apresentou uma expansão de 1,05\% na comparação com o segundo trimestre do ano anterior.

A assim chamada "nova matriz macroeconômica" foi uma tentativa do governo da presidente Dilma Rousseff de impulsionar o crescimento econômico através de uma combinação de desonerações tributárias, depreciação da taxa nominal de câmbio e redução da taxa básica de juros. A equipe econômica do governo partia do diagnóstico de que a desaceleração do crescimento econômico brasileiro era um problema de demanda agregada que tinha sua origem no recrudescimento da crise econômica internacional, em função dos problemas de endividamento soberano dos países da área do euro.

A “nova matriz" conseguiu produzir uma aceleração temporária do ritmo de crescimento econômico. No período compreendido entre o terceiro trimestre de 2012 ao primeiro trimestre de 2014, a economia brasileira consegue sustentar um ritmo anualizado de crescimento superior a $2,5 \%$.

A partir do segundo trimestre de 2014 o ritmo de crescimento entra em colapso. No segundo trimestre desse ano, o PIB apresenta uma queda de $0,33 \%$ na comparação com o mesmo período de 2013. O ritmo de decrescimento se acelera no terceiro trimestre para $0,58 \%$ na comparação com o 2013/T3. Após uma ligeira redução do ritmo de decrescimento no final de 2014, o ritmo de queda do nível de atividade econômica se acelera no primeiro trimestre de 2015, quando o PIB real apresenta uma contração de $1,87 \%$ na comparação com o primeiro trimestre de 2014. Na comparação entre o primeiro trimestre de 2014 e o primeiro trimestre de 2015 ocorre uma redução de 5,18 p.p. na taxa de crescimento do PIB.

Nos trimestres subsequentes o ritmo de queda do nível de atividade se aprofunda, fazendo que o PIB se contraia a um ritmo de 5,82\% no último trimestre de 2015. O movimento de queda do PIB continua ao longo do ano de 2016, mas a um ritmo decrescente, sugerindo que a economia brasileira se encontra numa trajetória de estabilização do nível de atividade, o qual provavelmente deve ser obtido no primeiro trimestre de 2017. Caso essa expectativa se confirme, o Brasil terá experimentado 11 trimestres consecutivos de queda do nível de atividade econômica.

O padrão de comportamento exibido pela economia brasileira desde o segundo trimestre de 2014 nos coloca duas questões para reflexão. A primeira questão refere-se ao porquê o ritmo de crescimento entrou em colapso a partir do segundo trimestre de 2014, ao invés de apresentar uma desaceleração mais gradual ao longo do ano? A segunda questão é por quais motivos o ritmo de queda do nível de atividade se intensifica a partir do primeiro trimestre de 2015?

A resposta a essas duas questões é de fundamental importância para podermos desenhar uma agenda de proposições de política econômica com vistas a retomada do crescimento. 


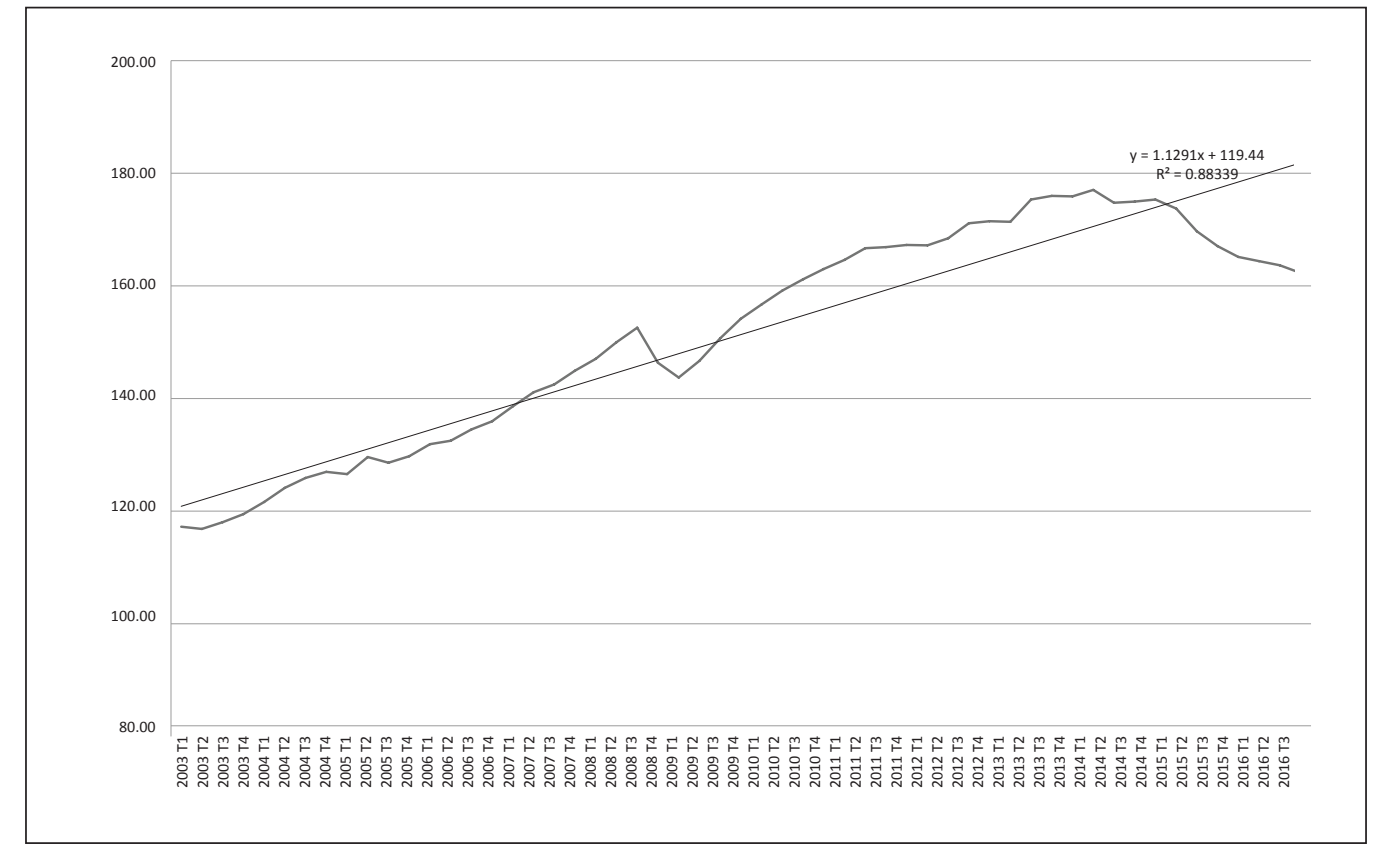

Fonte: Ipeadata. Elaboração do autor.

Figura 1 - Evolução do PIB real no Brasil (2003.T1-2016.T3).

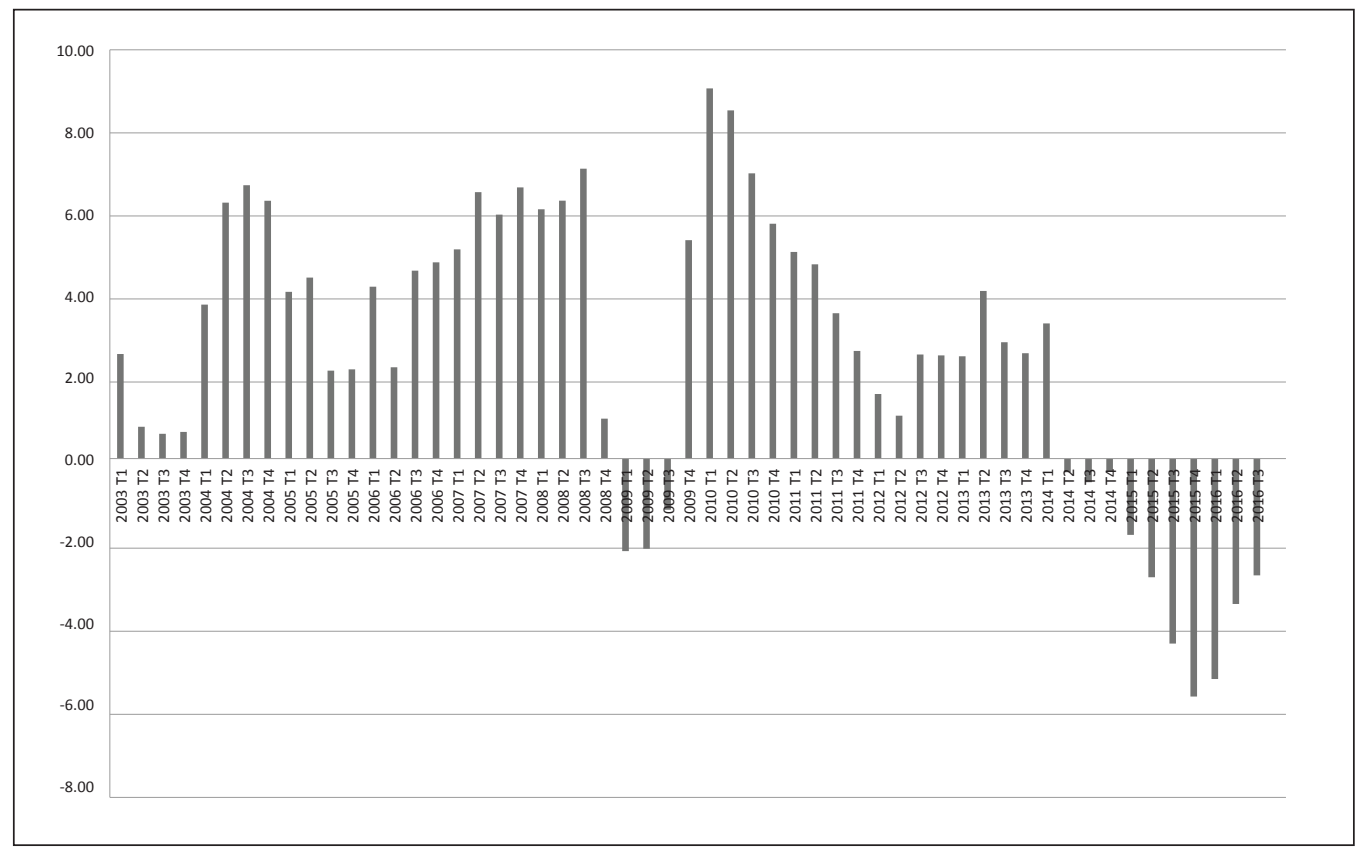

Fonte: Ipeadata. Elaboração do autor.

Figura 2 - Crescimento do PIB real no Brasil, Trimestre contra trimestre do ano anterior (2003.T1-2016.T3). 


\section{O colapso do investimento e o esmagamento de lucros}

A visível perda de sustentação sofrida pelo ritmo de crescimento da economia brasileira a partir do segundo trimestre de 2014 foi o resultado da expressiva queda da formação bruta de capital fixo (FBKF). Como podemos visualizar na Figura 3, os gastos com a FBKF apresentaram uma queda de $11 \%$ em termos reais no segundo trimestre de 2014 com relação ao mesmo período do ano anterior. Nos trimestres seguintes o movimento de queda do investimento tem continuidade, com a FBKF se reduzindo $13 \%$ no terceiro trimestre e outros $12 \%$ no último trimestre de 2014

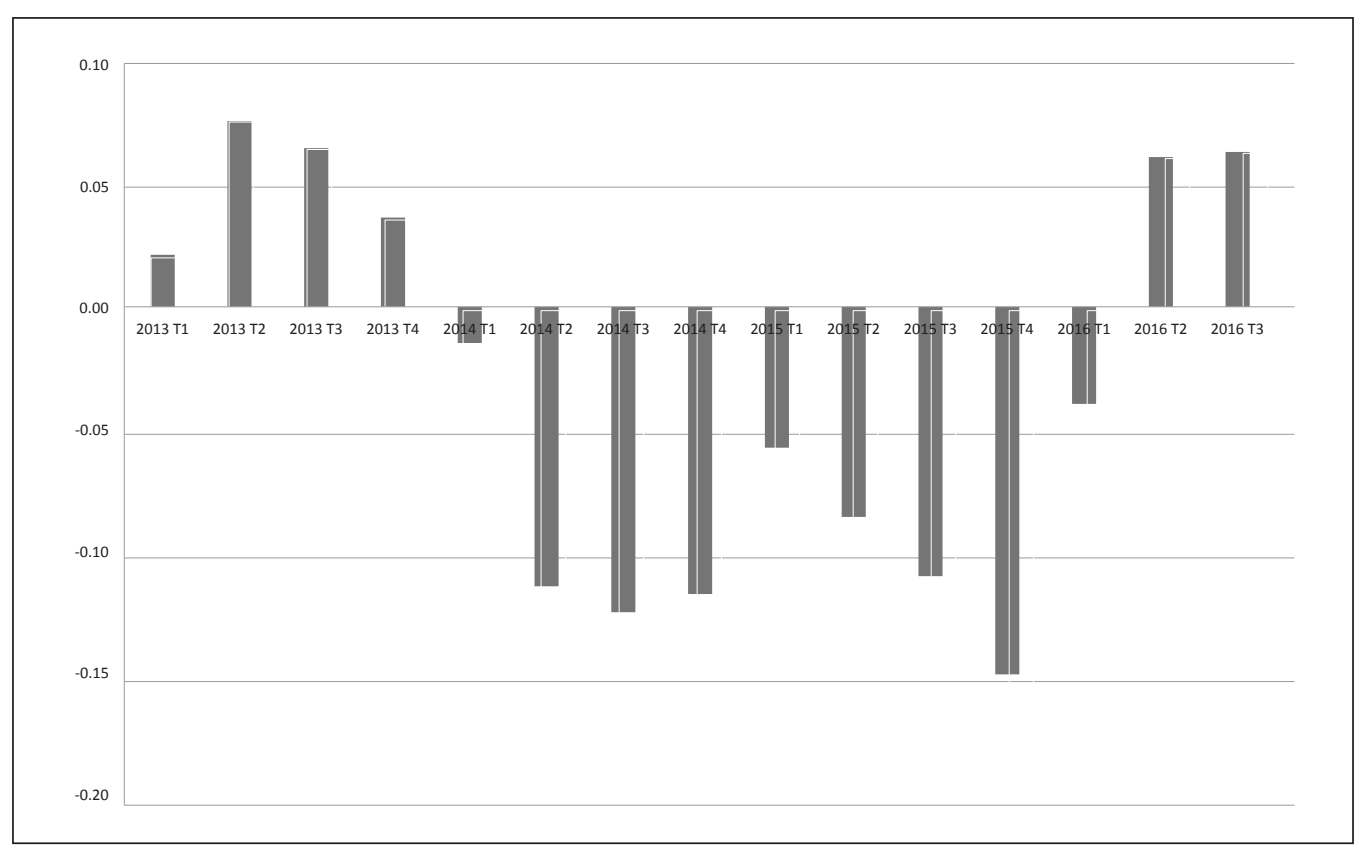

Fonte: Ipeadata. Elaboração do autor.

Figura 3 - Taxa de crescimento da formação bruta de capital fixo, na comparação com o mesmo trimestre do ano anterior (2013.T1-2016.T3).

Quais os fatores que explicam o colapso da FBKF ocorrida a partir do segundo trimestre de 2014? Mudanças abruptas dos gastos de investimento são, em geral, decorrência de mudanças nas expectativas dos empresários a respeito da taxa de retorno do capital, pois o custo do capital, largamente determinado pelo comportamento da taxa de juros, tende a apresentar um comportamento mais estável ao longo do tempo. A incerteza inerente ao processo de tomada de decisão numa economia capitalista faz que os empresários adotem convenções que lhes permitam lidar com o fato inescapável da extrema precariedade da base de conhecimento e informação sobre a qual podem formar suas expectativas sobre a taxa de retorno dos projetos de investimento. Uma dessas convenções consiste em supor que a situação atual irá persistir indefinidamente a não ser que se tenha uma razão concreta para esperar uma mudança (Keynes, 1936, p.148). 
Com base nessa convenção, as mudanças na taxa esperada de retorno do capital devem resultar de mudanças no valor observado dessa variável.

A Tabela 1, elaborada a partir dos dados de Rocca (2015), apresenta a evolução da Taxa de Retorno sobre o Capital Próprio (ROE) - das empresas brasileiras não financeiras de capital aberto e das maiores empresas não financeiras de capital fechado - e da Taxa Selic no período 2010-2014. A inspeção dessa tabela nos revela que a ROE apresenta uma nítida tendência de redução a partir de 2011, alcançando 4,3\% a.a. em 2014, valor inferior à inflação observada, tornando-a assim negativa em termos reais. Podemos observar também que a redução ocorrida na taxa Selic - um dos componentes do custo do capital - não foi suficiente para compensar a redução da rentabilidade do capital próprio das empresas brasileiras, sendo essa uma das razões pelas quais a "nova matriz macroeconômica" se mostrou incapaz de produzir uma aceleração de caráter permanente do ritmo de crescimento da economia brasileira (Oreiro; D’Agostini, 2017).

Tabela l - Evolução da taxa de retorno sobre o capital próprio e da Taxa Selic (2010-2014)

\begin{tabular}{l|l|l}
\hline & ROE & Selic \\
\hline 2010 & $16,50 \%$ & $9,80 \%$ \\
2011 & $12,50 \%$ & $11,70 \%$ \\
2012 & $7,20 \%$ & $8,50 \%$ \\
2013 & $7,00 \%$ & $8,20 \%$ \\
2014 & $4,30 \%$ & $10,90 \%$ \\
\hline
\end{tabular}

Fonte: Rocca (2015). Elaboração própria.

Quais as razões que explicam a tendência de queda da taxa de retorno do capital a partir de 2011 ? Estudo publicado pelo Cemec (2015) mostra que o principal fator da redução das taxas de retorno é a queda das margens de lucro das empresas não financeiras, as quais não tem conseguido transferir para os preços de venda a totalidade dos aumentos verificados em seus custos operacionais (Ibidem, p.10). Excluindo-se os casos nos quais as margens de lucro caíram em função das políticas de controle de preços adotadas pelo governo na tentativa de manter a inflação dentro das metas estabelecidas pelo Conselho Monetário Nacional, sem ter que recorrer ao aumento da taxa de juros - como foi o caso da Petrobras, da Eletrobras e das usinas de etanol -, o setor que apresentou a maior redução de margens foi a indústria (Ibidem, p.11). A queda das margens de lucro no setor industrial decorreu, por sua vez, do aumento do Custo Unitário do Trabalho (CUT), gerado pelo aumento dos salários acima do crescimento da produtividade do trabalho; em conjunto com a sobrevalorização da taxa de câmbio, a qual impediu o repasse do aumento do CUT para os preços dos produtos industriais devido à concorrência dos produtos importados. 
Outro fator que explica a queda dos gastos de investimento em 2014 foi a forte retração dos investimentos do Grupo Petrobras (Valor Econômico, 2017b). Em função dos efeitos combinados do elevado coeficiente de endividamento (medido pelo Ebit-da), da queda do preço do petróleo no mercado internacional e das implicações da Operação Lava Jato; o Grupo Petrobras reduziu os seus gastos investimento de 1,86\% do PIB em 2013, para 1,41\% do PIB em 2014, uma contração de 0.45 p.p. do PIB.

\section{Fatores amplificadores: realinhamento de preços relativos e a perda do espaço fiscal}

A queda acentuada dos gastos com a FBKF ocorrida em 2014 foi o estopim da recessão que se abateu sobre a economia brasileira; mas não explica o notável agravamento da intensidade do quadro recessivo observado em 2015; e muito menos a persistência desse quadro ao longo do ano 2016. Outros fatores contribuíram para amplificar os efeitos do colapso do investimento, aprofundando assim o mergulho na recessão.

Um primeiro fator amplificador foi o realinhamento súbito de preços relativos feito no início do segundo mandato da presidente Dilma Rousseff. As tarifas de energia elétrica, que haviam sido reduzidas em 2013, como parte da estratégia para manter a inflação dentro do intervalo de tolerância do sistema de metas, foram reajustadas em cerca de $50 \%$ com o intuito de recuperar a rentabilidade das empresas de distribuição de energia, que fora negativamente afetada pela política de controle de preços. A taxa nominal de câmbio também sofreu uma forte desvalorização nos três primeiros meses de 2015, passando de uma média de R\$ 2,66 em janeiro para R\$ 3,20 em março, uma depreciação de 20,3\% em apenas dois meses. ${ }^{2}$ Como resultado desse realinhamento dos preços relativos a inflação medida pela variação anualizada do IPCA saltou de 6,41\% no último trimestre de 2014, para 9,48\% no terceiro trimestre de 2015.

A aceleração da inflação resultou numa forte queda da renda real por trabalhador. Com base nos dados coletados em Oreiro e D'Agostini (2016), a taxa de crescimento da renda real por trabalhador se reduziu de $0,7 \%$ no último trimestre de 2014 (na comparação com igual período do ano anterior) para $-6,90 \%$ no segundo trimestre de 2015 . Essa queda da renda real por trabalhador foi um dos fatores que explica a forte contração dos gastos de consumo das famílias observado a partir do primeiro trimestre de 2015, o qual pode ser visualizado por intermédio da Figura 4.

Outro fator que contribuiu para a amplificação dos efeitos recessivos da queda dos gastos de investimento foi o comportamento da política fiscal. Segundo estudo publicado pela Secretaria de Política Econômica em maio de 2016 (SPE, 2016), a política fiscal no Brasil no período 2003-2015 foi, em geral, pró-cíclica; ou seja, adotou uma postura expansionista durante os períodos nos quais a economia crescia acima da sua tendência de longo prazo; e uma postura contracionista nos momentos em que a economia operava abaixo do potencial. 
A pró-ciclicidade da política fiscal brasileira se acentuou em 2015 em função da perda do espaço fiscaß ${ }^{\mathfrak{A}}$ decorrente da eliminação da capacidade de geração de superávit primário pelo Setor Público ao longo do ano de 2014. Esse fato colocou a dívida pública como proporção do PIB em trajetória de elevação, recriando temores a respeito de um possível default soberano. ${ }^{4}$ Para fazer frente a esse risco, o Ministério da Fazenda adotou um forte ajuste fiscal, ${ }^{5}$ concentrado na redução dos gastos de investimento do governo federal, os quais caíram de 1,34\% do PIB em 2014 para 0,93\% do PIB em 2015 (Valor Econômico, 2017b).

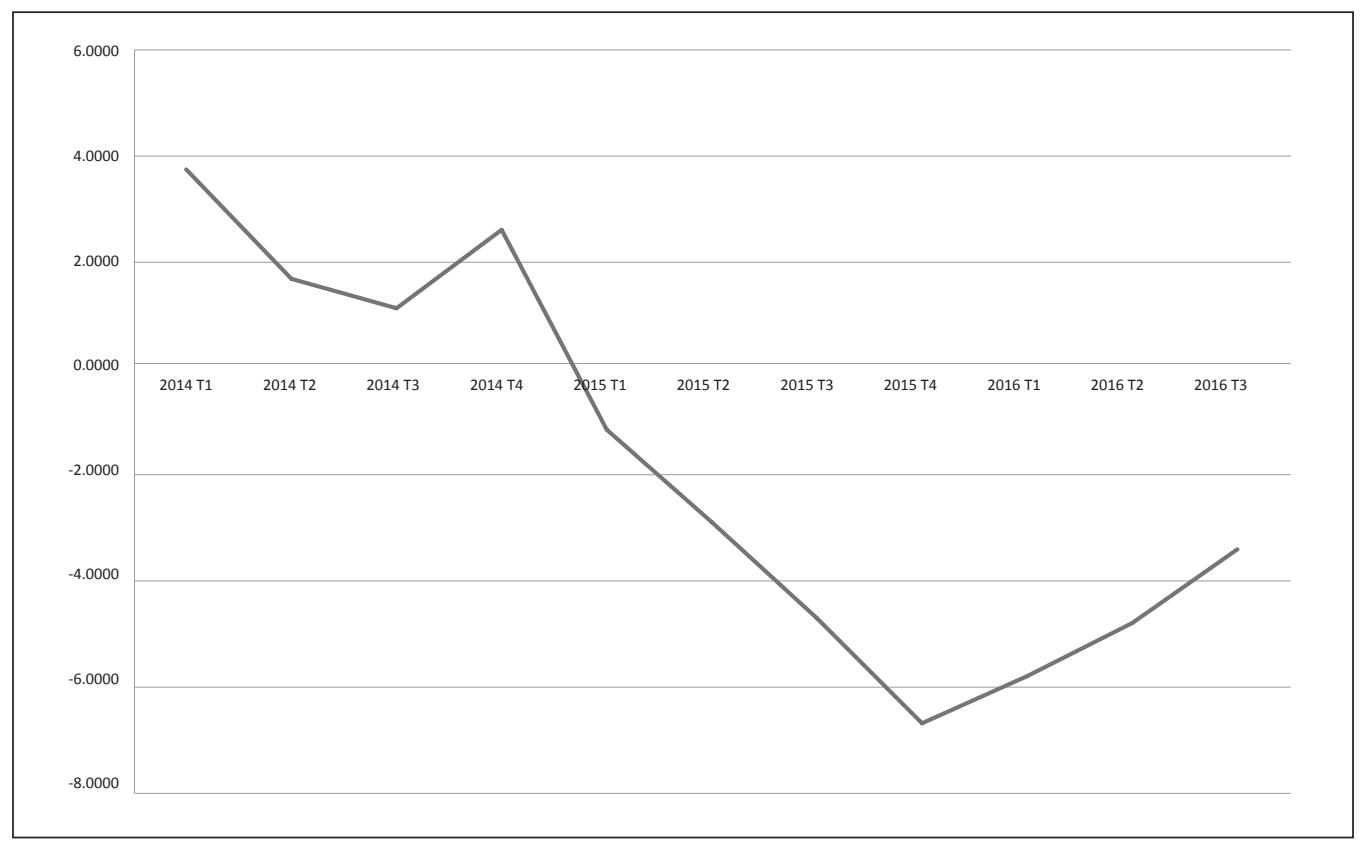

Fonte: Ipeadata. Elaboração do autor.

Figura 4 - Evolução do consumo final das famílias (2014.T1-2016.T3).

Para que se possa medir a contribuição da política fiscal para o agravamento do quadro recessivo da economia brasileira é necessário calcular o assim chamado impulso fiscal, o qual consiste na diferença entre o resultado primário estrutural no ano t e o resultado primário estrutural do ano $t-1$, multiplicado por - 1 . Assim, quando o resultado primário estrutural do ano $t$ for maior do que o do resultado do ano $\mathrm{t}-1$, o impulso fiscal será negativo, ou seja, a política fiscal será, portanto, contracionista, contribuindo assim para o agravamento do quadro recessivo; do contrário o impulso fiscal será positivo e a política fiscal será expansionista. O resultado primário estrutural é definido, por sua vez, como o resultado primário que é compatível com o PIB ao nível potencial, com os preços dos ativos ao nível de equilíbrio de longo prazo e descontado dos efeitos das receitas não-recorrentes (SPE, 2016). 
A evolução do resultado primário estrutural do setor público brasileiro para o período 2002-2015 pode ser observada na Figura 5.

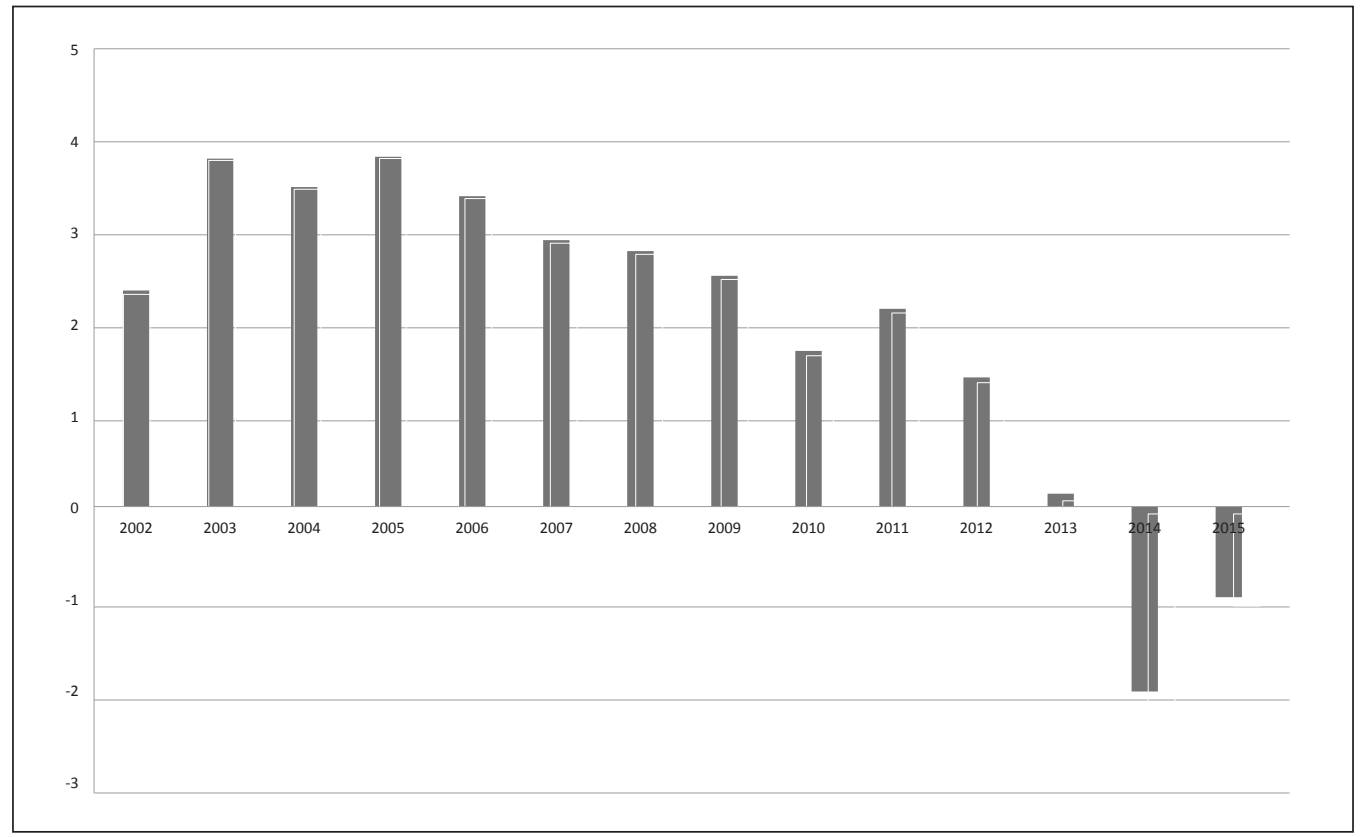

Fonte: SPE (2016). Elaboração do autor.

Figura 5 - Evolução do resultado primário estrutural do setor público (2002-2015).

Na Figura 5 podemos perceber uma nítida tendência de redução do resultado primário estrutural a partir de 2007. Essa tendência se acentua a partir de 2011, no primeiro mandato da presidente Dilma Rousseff. Em 2013 o resultado primário estrutural é praticamente nulo, tornando-se fortemente negativo em 2014. Um resultado primário estrutural negativo é claramente inconsistente com a solvência de médio/longo prazo do setor público, tornando inadiável a realização de um ajuste fiscal em 2015, justamente no momento em que a economia brasileira se encontra em recessão. Dessa forma, a política fiscal será fortemente contracionista em 2015, gerando um impulso fiscal de -1,02\% do PIB.

\section{Uma agenda de política econômica}

\section{para a retomada do crescimento}

Vimos nas seções anteriores que a grande recessão da economia brasileira foi o resultado de um colapso dos gastos de investimento, decorrência do "esmagamento de lucros", e de fatores que amplificaram os efeitos desse choque inicial sobre o nível de atividade econômica.

Nesse contexto, a solução para a crise passa inicialmente pelo restabelecimento das margens de lucro das empresas, o que exige (i) a redução do CUT na indústria e (ii) a manutenção da taxa de câmbio num patamar competitivo. 
Na Figura 6 podemos observar o comportamento da média móvel dos últimos 12 meses do CUT ${ }^{6}$ na indústria brasileira no período compreendido entre janeiro de 2014 e dezembro de 2016. Uma característica surpreendente da dinâmica do CUT é manutenção de uma clara tendência de crescimento dessa variável até maio de 2016, apesar da elevação bastante forte da taxa de desemprego. Dado o comportamento eminentemente pró-cíclico da produtividade do trabalho, a dinâmica do CUT revela que no Brasil existe uma forte resistência dos salários reais à queda. Essa resistência torna mais lento o processo de recuperação das margens de lucro da indústria, retardando assim a retomada dos investimentos industriais.

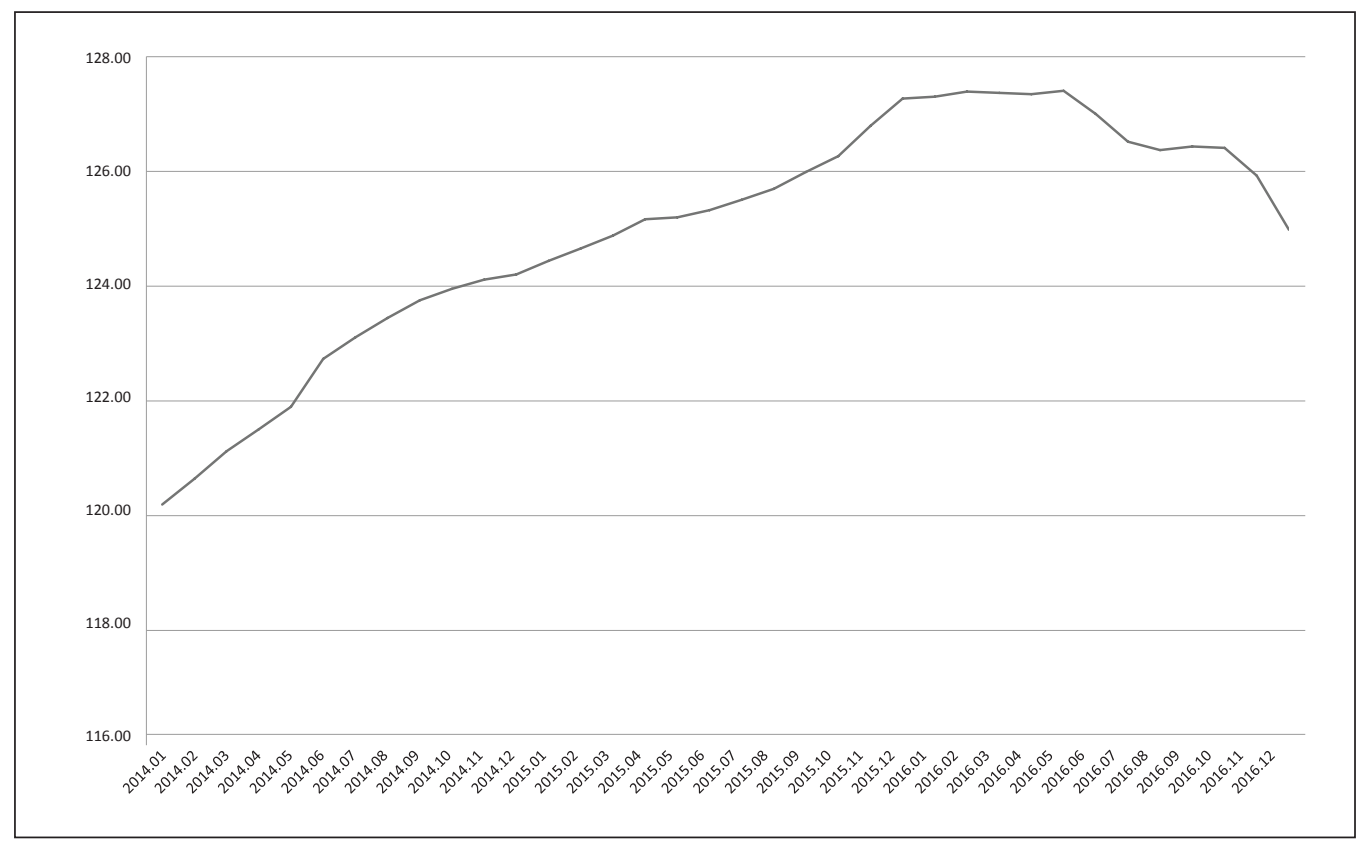

Fonte: Ipeadata. Elaboração do autor.

Figura 6 - Evolução do custo unitário do trabalho na indústria geral, média móvel dos últimos 12 meses (2014.01-2016.12).

Na Figura 6 observamos que a redução ocorrida no CUT após 2016 não foi suficiente para levar essa variável ao nível observado em janeiro de 2014. Dessa forma, podemos concluir que são necessárias medidas para reduzir a rigidez do salário real, ou seja, medidas que permitam uma redução do salário real para um nível compatível com o restabelecimento da competitividade e das margens de lucro da indústria. Uma medida concreta nesse sentido seria eliminar os mecanismos de indexação dos salários à inflação passada. Para tanto, o governo precisa mudar a regra de reajuste do salário mínimo, a qual vincula o reajuste anual do salário mínimo à inflação do ano anterior. Em função do assim chamado "efeito farol", pelo qual os reajustes do salário mínimo acabam sendo difundidos para toda a estrutural salarial da economia (Neri; Gonzaga; Camargo, 
2001), a atual regra de reajuste do salário mínimo é um dos fatores que enrijece o nível dos salários reais no Brasil. Uma regra alternativa seria fixar o reajuste anual do salário mínimo com base na soma entre o centro da meta de inflação e a média móvel dos últimos cinco anos do crescimento do PIB per-capita, conforme defendido por Oreiro e D'Agostini (2016). Essa regra é consistente com o crescimento dos salários reais a um ritmo aproximadamente igual a produtividade do trabalho no médio/longo-prazo, tendo impacto neutro sobre o CUT.

Seguindo Bresser-Pereira, Oreiro e Marconi (2016), a taxa de câmbio estará num patamar competitivo ou de "equilíbrio industrial" quando ela permite que as empresas domésticas que operam com tecnologia no estado da arte mundial sejam competitivas à nível internacional (Ibidem, p.72). ${ }^{7}$ A taxa de câmbio de equilíbrio industrial não é constante ao longo do tempo, mas varia em função das variações observadas no CUT entre a economia doméstica e seus principais parceiros comerciais.

A dinâmica da taxa nominal de câmbio US\$ $/ \mathrm{R}$ \& e da taxa de câmbio de equilíbrio industrial para a economia brasileira pode ser visualizada na Figura $7 .{ }^{8}$

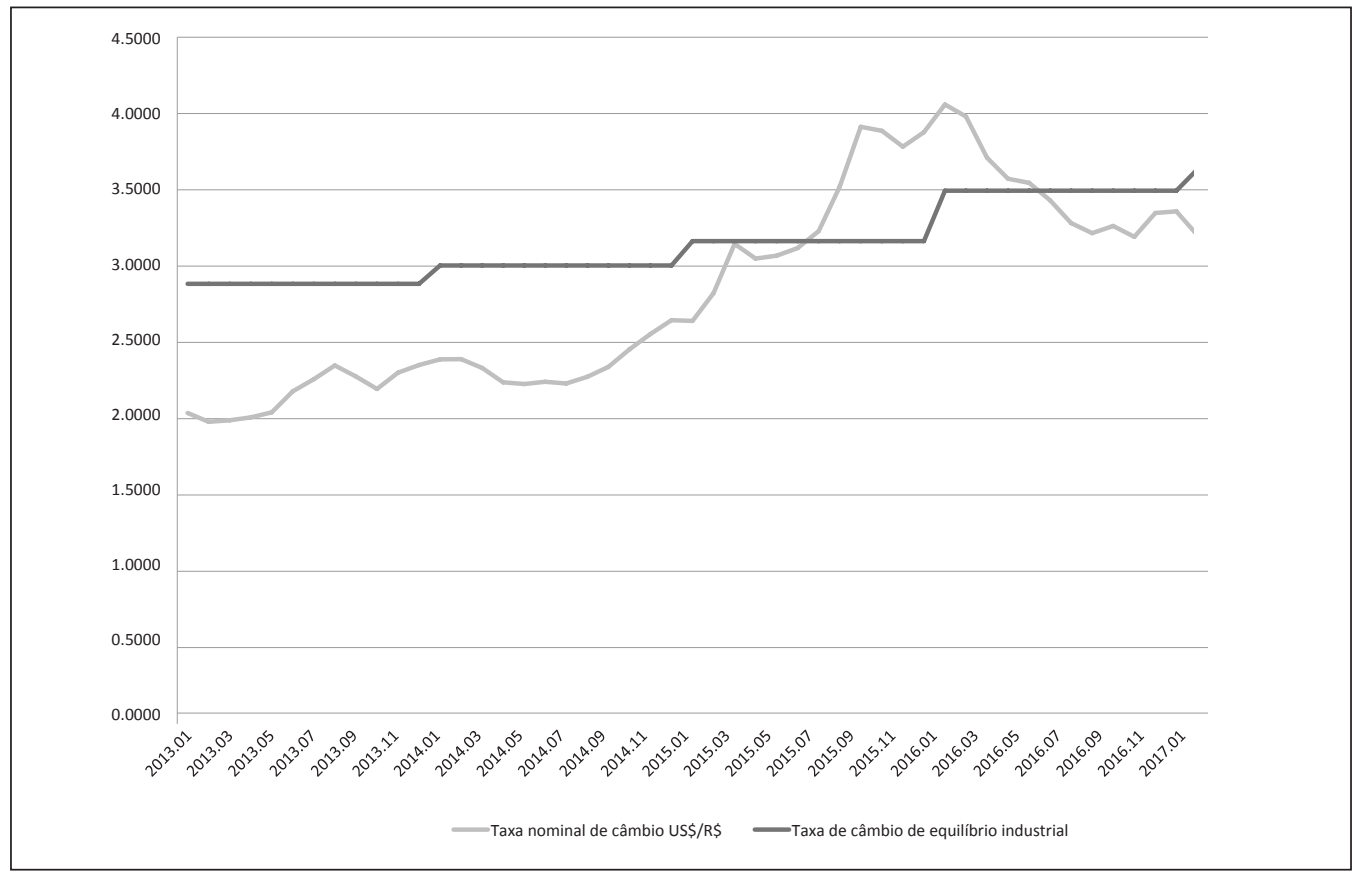

Fonte: Ipeadata. Elaboração do autor.

Figura 7 - Evolução da taxa nominal de câmbio US\$/R\$ e de taxa de câmbio de quilíbrio industrial (2013.01-2017.01).

Com base na Figura 7 podemos perceber que, após um breve período de tempo compreendido entre julho de 2015 e maio de 2016 , no qual a taxa de câmbio permaneceu subvalorizada, ou seja, acima do nível de equilíbrio industrial; a taxa de câmbio voltou a apresentar uma expressiva sobrevalorização. Essa 
situação é claramente incompatível com uma recuperação sustentada da produção industrial, sem a qual a retomada do crescimento da economia brasileira a taxas mais robustas é impossível.

Nesse contexto, o governo brasileiro precisa tomar medidas imediatas para reverter a sobrevalorização da taxa de câmbio no médio prazo. A mais importante dessas medidas começou a ser realizada em janeiro de 2016, por intermédio da aceleração do ritmo de redução da taxa de juros Selic pelo Banco Central do Brasil. A existência de um grande diferencial de taxa de juros (ajustada pelo prêmio de risco país) é um dos fatores estruturais para a tendência a sobrevalorização da taxa de câmbio observada no Brasil desde a implantação do Plano Real (Bresser-Pereira, 2007). Mas a flexibilização da política monetária não é suficiente. A forte correlação negativa observada entre a taxa real de câmbio e os termos de troca na economia brasileira (Oreiro; D’Agostini, 2016) apontam inequivocamente para a existência de doença holandesa no Brasil. Dessa forma, é necessário também que o governo brasileiro introduza um imposto sobre as exportações de commodities - como minério de ferro e soja - para reduzir a intensidade da doença holandesa (Bresser-Pereira, 2016). Marginalmente esse imposto poderia contribuir também para a realização do necessário ajuste fiscal.

Por fim, o governo brasileiro precisa avançar na agenda de reformas da arquitetura da política macroeconômica brasileira substituindo o sistema de metas nominais para o resultado primário por metas para o resultado primário estrutural (Oreiro, 2017). Essa mudança viabilizaria a introdução de uma política fiscal contracíclica no médio prazo, permitindo assim a compatibilização de dois objetivos distintos de política econômica, a saber: a estabilização do nível de atividade econômica e a solvência intertemporal do setor público.

\section{Notas}

I De 1945 até 1980 não houve um único ano no qual a variação do PIB brasileiro tenha sido negativo. As recessões eram "recessões de crescimento", ou seja, períodos nos quais a economia se expandia a taxas inferiores à sua tendência histórica. No período recessivo de 1980 a 1983 o PIB brasileiro caiu $6,3 \%$ em termos reais. Para o período 2013-2016 espera-se uma contração de 6,8\% do PIB (Safatle; Borges; Oliveira, 2016, p.30).

2 A desvalorização da taxa nominal de câmbio ocorrida no primeiro semestre de 2015 não foi, contudo, uma opção deliberada de política econômica; mas reflexo da queda acentuada dos termos de troca da economia brasileira. Com efeito, os termos de troca apresentaram uma contração de $9,47 \%$ entre o último trimestre de 2014 e o terceiro trimestre de 2015 (Oreiro; D’Agostini, 2016).

3 Com base em Eberly (2014) o espaço fiscal é definido como uma situação na qual o governo tem espaço para realizar uma política fiscal expansionista por muitos anos e, portanto, incorrer em déficits orçamentários persistentes por longos períodos sem colocar em risco a sua solvência intertemporal. Uma condição necessária para a existência de um 
espaço fiscal relevante é que a dívida pública como proporção do PIB seja relativamente baixa nos períodos de boom econômico, uma vez que o resultado primário requerido para a estabilização/redução da dívida pública como proporção do PIB é uma função crescente do nível de endividamento do governo.

$4 \mathrm{O}$ aumento do risco de default soberano por parte do governo brasileiro se deu mais fortemente no segundo semestre de 2015 quando o índice EMBI+ para o Brasil subiu cerca de 200 p.b (Oreiro; D’Agostini, 2016).

$5 \mathrm{O}$ ajuste fiscal realizado pelo ministério da Fazenda em 2015 teve impacto também sobre a oferta de crédito dos bancos públicos, na medida que as preocupações fiscais levaram a restrições à expansão dos empréstimos financiados pela dívida pública pelos bancos públicos (Canuto, 2017). Dessa forma, o ajuste fiscal teve como efeito secundário um choque financeiro negativo em 2015, fator esse que contribuiu decisivamente para a forte retração dos gastos de consumo das famílias.

6 Essa série foi construída a partir da série de massa salarial (real, deflacionado pela variação do INPC) da indústria geral e de produção industrial (quantum, indústria geral, índice dessazonalizado) obtidas no site do Ipeadata.

7 Para a metodologia de cálculo da taxa de câmbio de equilíbrio industrial ver Marconi (2012). A taxa de câmbio de equilíbrio industrial é calculada como o nível de taxa de câmbio que equaliza o custo unitário do trabalho na indústria entre a economia doméstica e seus principais parceiros comerciais.

8 A série de taxa de câmbio de equilíbrio industrial para o período (2013.01-2017.01) foi construída a partir da taxa de câmbio de equilíbrio industrial calculada por Marconi (2012) para o ano de 2011, atualizando-se a mesma pela diferença entre a variação anual do INPC no Brasil e a variação anual do IPC nos Estados Unidos.

\section{Referências}

BRESSER-PEREIRA, L. C. Macroeconomia da estagnação: crítica da ortodoxia convencional no Brasil pós-1994. São Paulo: Editora 34, 2007.

. Retenção cambial alíquota zero. Valor Econômico, 3 março 2016.

BRESSER-PEREIRA, L. C.; OREIRO, J. L.; MARCONI, N. Macroeconomia desenvolvimentista. Rio de Janeiro: Elsevier, 2016.

CANUTO, O. A natureza do ciclo de crédito brasileiro. The Huffington Post Brasil, 5 fev. 2017.

CEMEC. Fatores da queda do investimento 2010-2014. Nota CEMEC, mar. 2015.

EBERLY, J. Defining the reemerging role of fiscal policy. In: AKERLOF, G.; BLANCHARD, O.; ROMER, D.; STIGLITZ, J. What we have learned? Macroeconomic Policy after the Crisis. Cambridge (Mass.): The MIT Press, 2014.

KEYNES, J. M. The general theory of employment, interest and money. London: Macmillan, 1936.

MARCONI, N. The Industrial Equilibrium Exchange Rate in Brazil: an estimation. Brazilian Journal of Political Economy, v.32, n.4, 2012.

NERI, M.; GONZAGA, G.; CAMARGO, J. M. Salário mínimo, 'Efeito Farol' e pobreza. Brazilian Journal of Political Economy, v.21, n.82, 2001. 
OREIRO, J. L. Macroeconomia do desenvolvimento: uma perspectiva keynesiana. Rio de Janeiro: LTC, 2016.

Uma nova política fiscal. Diário de Comércio e Indústria, 23 fev. 2017.

OREIRO, J. L.; D'AGOSTINI, L. From Lula Growth Spectacle to the Great Recession (2003-2015): Lessons of the management of the macroeconomic tripod and macroeconomic challenges for restoring economic growth in Brazil. 2016. Disponível em: <http://joseluisoreiro.com.br/site/link/eca7eac82fl6c20f9c2c75cb375ecbc01489ea2f.pdf.>

Macroeconomic Policy Regimes, Real Exchange Rate Over-Valuation and Performance of Brazilian Economy (2003-2015). Journal of Post Keynesian Economics, no prelo (2017).

ROCCA, C. A. Ajuste fiscal e a recuperação do investimento. Apresentação $14^{\circ}$ Seminário CEMEC de Mercado de Capitais. São Paulo, 2015.

SAFATLE, C.; BORGES, J.; OLIVEIRA, R. Anatomia de um desastre: os bastidores da crise econômica que mergulhou o país na pior recessão de sua história. São Paulo: s. n., 2016.

SECRETARIA DE POLÍTICA ECONÔMICA. Resultado fiscal estrutural: novas estimações para a metodologia proposta. Maio, 2016.

VALOR ECONÔMICO. Índice de atividade do BC recua $0,36 \%$ no $4^{\circ}$ trimestre. 17 fev. 2017a.

Investimento federal cai de $3,25 \%$ do PIB para 1,9\% do PIB entre 2013 e 2016. 22 fev. 2017 b.

RESUMO - Este artigo tem por objetivo discutir as causas da grande recessão da economia brasileira (2014-2016), bem como apresentar uma agenda de política econômica com vistas à superação dessa crise e retomada do crescimento em bases sustentadas. Argumenta-se que a grande recessão foi causada pela queda acentuada dos gastos de investimento ao longo do ano 2014, cuja origem se encontra na redução das margens de lucro das empresas não financeiras decorrente da elevação do custo unitário do trabalho e da sobrevalorização da taxa de câmbio. Os efeitos recessivos do colapso do investimento foram amplificados pelo realinhamento brusco dos preços relativos ocorrido no primeiro semestre de 2015, e pela contração fiscal executada pelo Ministério da Fazenda no primeiro ano do segundo mandato da presidente Dilma Rousseff. A realização de uma contração fiscal no meio de uma recessão foi, contudo, decorrência da "perda de espaço fiscal" causada pela tendência de redução do resultado primário estrutural observada desde 2007. A superação da atual crise econômica exige a recuperação das margens de lucro das empresas não financeiras, o que requer uma mudança na regra de reajuste do salário mínimo, a continuidade da flexibilização da política monetária e a adoção de um imposto de exportação de commodities. Também é necessário eliminar o caráter pró-cíclico da política fiscal por intermédio da introdução de metas para o resultado primário estrutural.

PALAVRAS-CHAVE: Crise econômica no Brasil, Esmagamento de lucros, Política fiscal. 
ABSTRACT - The aim of the present article is to discuss the causes of the great recession of the Brazilian economy (2014-2016), as well as to present an economic policy agenda to restore sustained economic growth. It is argued that the great recession was caused by a huge reduction of investment expenditures in 2014, derived from lower profit margins of nonfinancial companies caused by an increase in unit labor costs and an overvalued exchange rate. The recessionary effects of investment collapse were amplified by the sudden realignment of relative prices on the first semester of 2015, and also by the fiscal contraction that the Ministry of Finance carried out in the first year of President Dilma Rousseff's second mandate. The occurrence of a fiscal contraction amidst a severe recession was due to the "evaporation of fiscal space" caused by the long-term trend of lower primary surplus observed since 2007. Overcoming the current crisis requires an increase in profit margins, which in turn requires a change in the minimum wage laws, the continuation of monetary policy easing and the adoption of an export tax on commodities. It is also necessary to eliminate the procyclical feature of Brazilian fiscal policy by introducing targets for structural primary surplus.

KEYWORDS: Economic crisis in Brazil, Profit squeeze, Fiscal policy.

José Luis Oreiro é professor do Departamento de Economia da Faculdade de Economia, Administração e Contabilidade da Universidade de Brasília, pesquisador Nível IB do CNPq e pesquisador associado do Centro de Estudos do Novo-Desenvolvimentismo (FGV-SP). Foi presidente da Associação Keynesiana Brasileira (2013-2015).

@ - joreirocosta@yahoo.com.br

Recebido em 2.3.2017 e aceito em 30.3.2017.

I Faculdade de Economia, Administração e Contabilidade, Universidade de Brasília, Brasília / Distrito Federal, Brasil. 